\title{
Sulphasalazine: a safe, effective agent for prolonged control of rheumatoid arthritis. A comparison with sodium aurothiomalate
}

\author{
D E BAX AND R S AMOS \\ From the Rheumatism Research Unit, Nether Edge Hospital, Sheffield
}

SUMMARY The place of sulphasalazine in the management of rheumatoid arthritis over prolonged periods of time has been compared and contrasted with that of sodium aurothiomalate. One hundred and forty-three patients (59 on sulphasalazine, 84 on sodium aurothiomalate) have been treated for periods of up to 42 months. Sulphasalazine is highly effective for some patients, though probably less frequently than sodium aurothiomalate. However, its safety profile is far superior, and very long-term treatment with sulphasalazine is a safe option for treatment of rheumatoid arthritis.

Key words: gold, salazopyrin, drug-induced remission.

Sodium aurothiomalate therapy has an established place in the management of rheumatoid arthritis and, despite the wide range of toxic effects which complicate its use, many rheumatologists would agree that it can produce profound benefits for some patients. It has been used for far longer than other members of the group of remission-inducing or second-line antirheumatic drugs and has therefore set standards against which other therapies may be measured. Recently it has been suggested that sulphasalazine (salicyl-azo-sulphapyridine) should be considered to be an additional member of this group,$^{1-5}$ though these open and controlled clinical trials were too short, all being 12 months or less, to permit firm conclusions to be made about its place in the long-term treatment of rheumatoid arthritis.

We have examined the frequency of success and the reasons for failure of sulphasalazine therapy in a large group of rheumatoid patients where the potential treatment periods ranged from 24 to 42 months. To date no other published data cover such a time span of sulphasalazine use. We have compared the profile of clinical benefits and adverse effects of sulphasalazine with that of a similar group of patients treated with sodium aurothiomalate over the same time periods.

Accepted for publication 19 October 1984.

Correspondence to Dr D E Bax, Senior Registrar, Rheumatism Research Unit, Nether Edge Hospital, Sheffield S11 9EL.

\section{Patients and methods}

The patients reported all had active rheumatoid arthritis and attended one rheumatology clinic. Sodium aurothiomalate and sulphasalazine were used almost interchangeably in the presence of active inflammatory disease and there was no conscious reason for choosing one rather than the other, except that sulphasalazine was avoided in patients with a recent history of severe dyspepsia. All patients starting either drug between April 1980 and October 1981 are included. The minimum $\delta$ potential treatment period was 24 months, with some patients receiving therapy for up to 42 months.

All patients had active polyarthritis with more than three painful swollen joints and usually pro-

Table 1 Definition of treatment outcome

\begin{tabular}{ll}
\hline Success & $\begin{array}{l}\text { Still on therapy at } 2 \text { years } \\
\text { Active joint count } 0 \text { or } 1^{*}\end{array}$ \\
Morning stiffness less than 30 minutes & $\begin{array}{l}\text { Discontinuation of therapy within } 2 \text { years } \\
\text { whatever the reason }\end{array}$ \\
Partial success & $\begin{array}{l}\text { Still on therapy at } 2 \text { years } \\
\text { Subjective or objective evidence, or both, of } \\
\text { improvement without meeting criteria of } \\
\text { successful therapy }\end{array}$ \\
\hline
\end{tabular}

${ }^{*}$ All metacarpophalangeal joints, proximal interphalangeal joints, or metatarsophalangeal joints are considered as single joint groups. 
Table 2 Characteristics of patients

\begin{tabular}{lll}
\hline & Sulphasalazine & $\begin{array}{l}\text { Sodium } \\
\text { aurothio- } \\
\text { malate }\end{array}$ \\
\hline Total & 59 & 84 \\
Males (\%) & $22(37)$ & $21(25)$ \\
Seropositive (\%) & $45(76)$ & $67(80)$ \\
Age in years (range) & $54(16-73)$ & $55(30-74)$ \\
Disease duration in years (range) & $5(1-18)$ & $6(1-30)$ \\
$\begin{array}{l}\text { Initial erythrocyte sedimentation } \\
\text { rate in mm in first hour (range) }\end{array}$ & $56(2-135)$ & $61(13-135)$ \\
Oral corticosteroids (\%) & $22(37)$ & $35(42)$ \\
\hline
\end{tabular}

longed morning stiffness. The decision to treat was made after considering symptoms and physical signs, without reference to the erythrocyte sedimentation rate. The decision was made by the same physician in all cases. Treatment was judged to have been successful or otherwise according to simple clinical criteria (Table 1).

Intramuscular sodium aurothiomalate $50 \mathrm{mg}$ was administered weekly, decreasing when marked improvement was seen to $50 \mathrm{mg}$ on alternate weeks. This dose was then continued indefinitely. Mild rashes or mild proteinuria were managed by lowering the dose or frequency of administration or by temporary withdrawal. The drug was permanently withdrawn only if extensive or persistent skin rashes or heavy proteinuria or more rarely other potentially serious unwanted effects, such as colitis or thrombocytopenia, occurred.

Sulphasalazine was administered as the enteric coated preparation and was introduced at $1 \mathrm{~g}$ daily, increasing to $2 \mathrm{~g}$ daily after one week and continued at this dose indefinitely. Mild unwanted reactions were managed by dose reduction or by a slower increase to the maintenance dose.
Table 3 Results of therapy and reasons for failure

\begin{tabular}{llccc}
\hline $\begin{array}{l}\text { Treatment } \\
\text { outcome }\end{array}$ & \multicolumn{2}{l}{$\begin{array}{l}\text { Sulphasalazine } \\
\text { no. }\end{array}$} & $(\%)$ & \multicolumn{2}{c}{$\begin{array}{l}\text { Sodium } \\
\text { no. }\end{array}$} & $\begin{array}{c}\text { aurothiomalate } \\
(\%)\end{array}$ \\
\hline Success & $19^{*}$ & $(32)$ & $37^{*}$ & $(44)$ \\
Partial success & 11 & $(19)$ & 10 & $(12)$ \\
Failure & 29 & $(49)$ & 37 & $(44)$ \\
$\quad$ Toxicity & 6 & $(10)$ & 31 & $(37)$ \\
$\quad$ Inefficacy & 23 & $(39)$ & 6 & $(7)$ \\
Total & 59 & & 84 & \\
\hline
\end{tabular}

${ }^{*}$ Fifteen sulphasalazine and 29 sodium aurothiomalate patients satisfy the American Rheumatism Association criteria for complete remission.

Some patients were taking oral corticosteroids but had been on a stable dose before starting sodium aurothiomalate or sulphasalazine, and this was continued unchanged or reduced if their clinical state allowed. A number of patients were admitted to hospital and some received intra-articular injections. In almost every case these events occurred early during the period of sodium aurothiomalate or sulphasalazine therapy.

The statistical analyses used were Student's $t$ test for comparing paired data, the $\chi^{2}$ test, and logistic regression methods. ${ }^{6}$ Statistical significance was taken as $\mathrm{p}<0.05$.

\section{Results}

The two groups of patients were broadly similar before treatment (Table 2).

$32 \%$ of the sulphasalazine group and $44 \%$ of the sodium aurothiomalate group had had a highly satisfactory long-term response. Fifteen of 19 good responders in the sulphasalazine group and 29 of 37 in the sodium aurothiomalate group satisfied the American Rheumatism Association criteria for com-

Table 4 Change in mean erythrocyte sedimentation rate (SD) during therapy (mm/h)

\begin{tabular}{lllll}
\hline Drug & $\begin{array}{l}\text { Treatment } \\
\text { outcome }\end{array}$ & Before & After & $\begin{array}{l}\text { Significance } \\
p\end{array}$ \\
\hline Sulphasalazine & All & $56(31)$ & $41(32)$ & $<0 \cdot 001$ \\
& Success & $46(27)$ & $12(8)$ & $<0 \cdot 001$ \\
& Partial success & $60(31)$ & $41(13)$ & $<0 \cdot 05$ \\
& Failure & $59(32)$ & $59(32)$ & NS \\
Sodium & All & $61(29)$ & $27(28)$ & $<0 \cdot 001$ \\
aurothiomalate & Success & $56(26)$ & $13(10)$ & $<0 \cdot 001$ \\
& Partial success & $67(30)$ & $30(29)$ & $<0 \cdot 01$ \\
& Failure & $64(31)$ & $37(35)$ & $<0 \cdot 001$ \\
\hline
\end{tabular}

${ }^{*}$ Current erythrocyte sedimentation rate or at discontinuation of therapy (Student's $t$ test for paired data). NS=not significant. 
Table 5 Adverse effects of therapy necessitating withdrawal

\begin{tabular}{lll}
\hline Adverse effect & $\begin{array}{l}\text { Sulphasalazine } \\
\text { (no.) }\end{array}$ & $\begin{array}{l}\text { Sodium } \\
\text { aurothiomalate } \\
\text { (no.) }\end{array}$ \\
\hline Rash & 1 & 18 \\
Proteinuria & 0 & 9 \\
Haematuria & 0 & 2 \\
Nausea & 3 & 0 \\
Gastrointestinal upset & 1 & 0 \\
Depression & 1 & 0 \\
Thrombocytopenia & 0 & 1 \\
Dyspnoea & 0 & 1 \\
Total & $6(10 \%)$ & $31(37 \%)$ \\
\hline
\end{tabular}

plete remission of disease ${ }^{7}$ and had done so for more than one year (Table 3 ).

There were significant falls in erythrocyte sedimentation rate with both drugs, reflecting the observed clinical improvement (Table 4). With sodium aurothiomalate all groups showed a fall in erythrocyte sedimentation rate during therapy, whereas with sulphasalazine only those patients classified as having a successful or partially successful outcome to treatment showed a significant fall.

Almost half of the patients in both groups discontinued therapy within two years and therefore failed to gain long-term benefits. Treatment failure occurred for very different reasons. Most patients withdrawing from sodium aurothiomalate did so because of toxicity that did not respond to dose modification, despite definite clinical improvement, whereas of those treated with sulphasalazine very few withdrew for this reason. Most patients withdrawn from sulphasalazine had failed to derive any measurable clinical benefits from the drug. The incidence and nature of adverse effects from sodium aurothiomalate and sulphasalazine necessitating withdrawal in our patients are shown in Table 5 .

Seropositivity, sex, disease duration, periods of inpatient therapy, the use of intra-articular or oral corticosteroids, and initial erythrocyte sedimentation rate had no significant influence on the eventual outcome (Table 6).

\section{Discussion}

The only previous long-term follow up study of patients with rheumatoid arthritis treated with sulphasalazine was reported by Svartz in $1948 .^{8}$ However, her study was different from ours, since most of her patients received only a short course of sulphasalazine during a period of hospital treatment; after discharge from hospital they were assessed between two and six and a half years later.

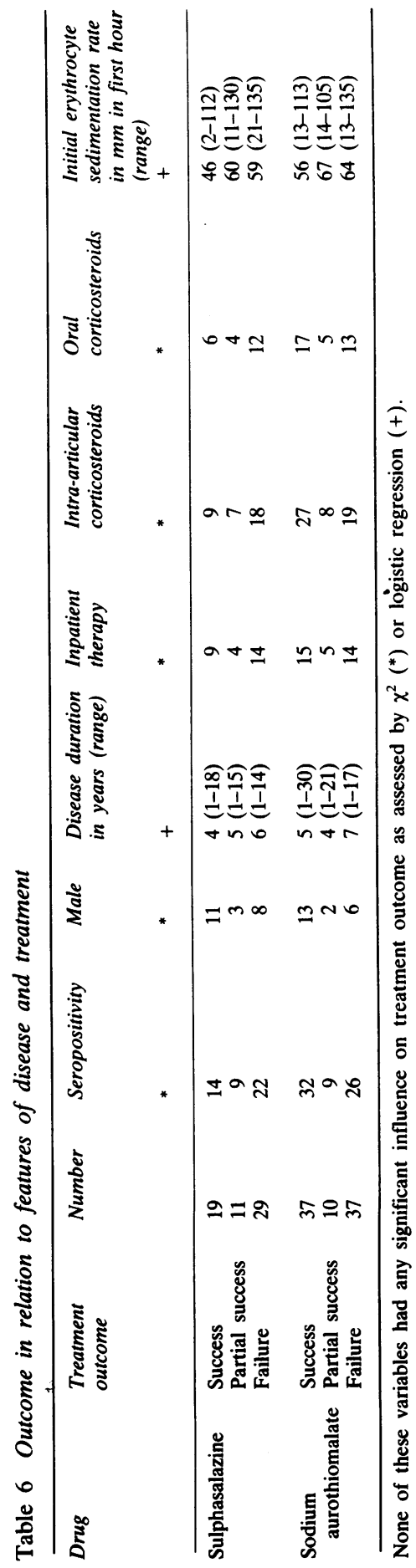


A number of the patients appeared to derive long-term benefit from sulphasalazine, and the value of this drug has been demonstrated again in recent controlled clinical trials. ${ }^{45}$. These studies however were short, lasting from four to six months and excluded those patients concurrently receiving oral corticosteroids or those undergoing inpatient treatment, and in one case $e^{4}$ early drop outs were replaced. In such situations sulphasalazine was reported to be as efficacious as sodium aurothiomalate or penicillamine, but from these studies it is not possible to determine the frequency of sustained significant improvement with sulphasalazine.

Unlike these recent studies we have examined the efficacy of sulphasalazine and sodium aurothiomalate against the varied background of normal clinical practice. The only exclusion for sulphasalazine was a patient with a recent history of severe dyspepsia, and none arose for sodium aurothiomalate. By adopting simple though stringent criteria for treatment outcome we have been able to identify the proportion of patients achieving a satisfactory outcome and maintaining it for long periods. This was not a randomised prospective trial, but all patients were treated for similar reasons by the same physician, and we therefore felt it reasonable to examine our long-term experience with these drugs.

Treatment was very successful for $32 \%$ of sulphasalazine and $44 \%$ of sodium aurothiomalate treated patients, and this success has been maintained for 24-42 months to date. All these patients look and feel much better, and most satisfy the American Rheumatism Association criteria ${ }^{7}$ for complete remission and have done so for at least one year.

With sulphasalazine good results were achieved with few risks; toxic effects were annoying rather than serious, and the main reason for stopping sulphasalazine was because patients failed to respond. In contrast the main reason for stopping sodium aurothiomalate therapy was toxicity, though many patients were improving at the time of withdrawal. All such patients have subsequently deteriorated. The low incidence of toxicity with sulphasalazine may reflect our routine use of the enteric coated preparation and our policy of encouraging patients with less severe reactions to continue taking the drug. The adverse effects of sodium aurothiomalate, however, were more unpleasant than those of sulphasalazine and despite either encouragement or a lowered dose once present usually resulted in the treatment being stopped.

It was not possible to identify any factor that would predict the efficacy of treatment with either sulphasalazine or sodium aurothiomalate. Although intra-articular corticosteroid injections and admission to hospital are known to have beneficial shortterm effects, ${ }^{910}$ we found neither these nor a number of other variables including seropositivity, disease duration, initial erythrocyte sedimentation rate, or the prior use of oral corticosteroids (Table 6) had any influence on the long-term outcome. There was a trend for men to do better than women, especially with sulphasalazine (Table 6), but this difference did not reach statistical significance.

The erythrocyte sedimentation rate was not used to determine whether drug therapy should be started nor did it influence the classification of treatment outcome. We nevertheless examined the changes in the erythrocyte sedimentation rate during treatment to see whether they complemented the clinical observations. Significant falls were seen only in those sulphasalazine treated patients considered to have shown a favourable long-term response, whereas with sodium aurothiomalate the erythrocyte sedimentation rate fell significantly in all treatment outcome groups (Table 4). This presumably reflects the fact that withdrawal from sodium aurothiomalate usually occurred because of problems of toxicity despite improvement in the arthritis, whereas sulphasalazine was generally stopped for lack of efficacy.

The results suggest that when sulphasalazine works well the outcome is similar to that observed with therapy with sodium aurothiomalate. Prolonged disease remission is seen in a substantial minority of patients treated with either drug. Primary treatment failure with sulphasalazine is much more frequent than with sodium aurothiomalate, but the safety profile of sulphasalazine is far superior. Treatment failure with sulphasalazine can generally be identified within three months, ${ }^{24}$ and it is now our policy to use sulphasalazine before sodium aurothiomalate, thus ensuring that at least one third of our patients are not exposed to the much greater hazards of sodium aurothiomalate therapy.

We are grateful for the help given by Miss M S Greaves and Mrs Pat Drake in the preparation of this paper.

\section{References}

1 McConkey B, Amos R S, Butler E P. Crockson R A, Crockson A P. Walsh L. Salazopyrin in rheumatoid arthritis. Agents Actions 1978; 8: 438-41.

2 McConkey B, Amos R S, Durham S, Forster P J G, Hubball S, Walsh L. Sulphasalazine in rheumatoid arthritis. $\mathrm{Br}$ Med $J$ 1980; 280: 442-4.

3 Bird H A, Dixon J S, Pickup M E, et al. A biochemical assessment of sulphasalazine in rheumatoid arthritis. J Rheumatol 1982 ; 9: 36-45.

4 Neumann V C, Grindulis K A, Hubball S, McConkey B, 
Wright V. Comparison between penicillamine and sulphasalazine in rheumatoid arthritis. $\mathrm{Br}$ Med J 1983; 287: 1099-102.

5 Pullar T, Hunter J A, Capell H A. Sulphasalazine in rheumatoid arthritis: a double blind comparison of sulphasalazine with placebo and sodium aurothiomalate. $\mathrm{Br}$ Med J 1983;287: 1102-4.

6 Anderson S, Auquier A, Hauck W W, Oakes D, Vandaele W, Weisberg H I. Statistical methods for comparative studies. Chichester: Wiley, 1980.

7 Pinals R S, Masi A T, Larsen R A. Preliminary criteria for clinical remission in rheumatoid arthritis. Arthritis Rheum 1981 w. 24: 1308-15.

8 Svartz N. The treatment of rheumatic polyarthritis with acid aze্⿸尸 compounds. Rheumatism 1948; 4: 180-5.

9 Duthie J J R, Brown P E, Truelove L H, Baragar F D, Lawrie A J. Course and prognosis in rheumatoid arthritis. A furthe report. Ann Rheum Dis 1964; 23: 193-202.

10 Lee P, Kennedy A C, Anderson J, Buchanan W W. Benefits of hospitalization in rheumatoid arthritis. $Q J$ Med 1974; 205-14. 